\title{
El uso de Twitter por parte de los principales candidatos en las campañas electorales para las elecciones generales españolas: 2011 y 2015. ¿Brecha digital y generacional?
}

\author{
The use of Twitter by the main candidates in the general election campaigns \\ in Spain: 2011 and 2015. Is there a digital and generational gap?

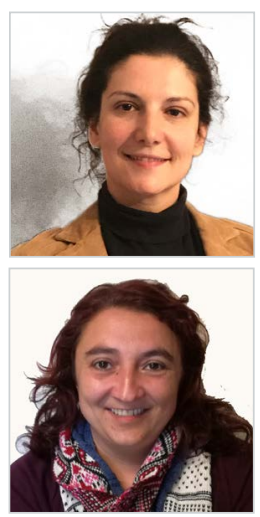 \\ Laura Cervi. Profesora asociada de la Facultad de Ciencias de la Comunicación de la Universitat Autònoma de \\ Barcelona y doctora en Ciencias Políticas por la Universitá di Pavia, Italia, con la investigación "Nazionalismo e \\ mercato elettorale: il caso catalano" en Comunicación Política. Finalmente, Laura Cervi se licenció en Ciencias \\ Políticas por la Universitá di Pavia, Italia, con un trabajo e investigación realizado en Estados Unidos. \\ Universitat Autònoma de Barcelona \\ laura.cervi@uab.cat \\ ORCID 0000-0002-0376-0609 \\ Núria Roca Trenchs. Doctoranda del programa de doctorado en Comunicación y Periodismo en la Universitat \\ Autònoma de Barcelona. Máster oficial de Investigación en Comunicación y Periodismo en la Universitat Autò- \\ noma de Barcelona. Licenciada en Comunicación Audiovisual en la Universitat Oberta de Catalunya, Posgrado \\ de Periodismo Digital en la Universitat Oberta de Catalunya y licenciada en Filosofía por la Universitat Autònoma \\ de Barcelona. \\ Universitat Autònoma de Barcelona \\ nuria.rocat@e-campus.cat
}

ORCID 0000-0002-9389-5098

Recibido: 28/12/2017 - Aceptado: 11/04/2018

\section{Resumen:}

¿Los candidatos usan Twitter para relacionarse más directamente con el electorado? En esta investigación nos preguntamos sobre el uso cuantitativo y cualitativo de esta red por parte de los principales candidatos durante las campañas electorales españolas de 2011 y 2015. Nos planteamos si existe una brecha digital entre los candidatos de la "vieja" y "nueva" política. Cuantitativamente analizamos los tuits, retuits, respuestas, seguidores y personas a quienes siguen, y los "me gusta" de los candidatos. Cualitativamente valoramos el uso informativo, deliberativo y de participación. Los resultados demuestran que no existe dicha brecha digital y que, de hecho, los candidatos estuvieron lejos de proponer estrategias innovadoras de comunicación más directa con los electores.

\section{Palabras clave:}

Campañas electorales, brecha digital y generacional, elecciones generales 2011 y 2015, España, Twitter
Received: 28/12/2017 - Accepted: 11/04/2018

\section{Abstract:}

Do candidates use Twitter to communicate more directly with their electorate? In this investigation, we question the quantitative and qualitative way in which this social network was used by the main candidates during the Spanish electoral campaigns of 2011 and 2015. The aim is to establish whether there is a digital gap between the candidates of the "old" and "new" politics. Quantitatively, we analysed tweets, retweets, replies, followers/followings, and "likes". Qualitatively, we analysed the informative, deliberative and participative way in which candidates used this network. The results show that there is no digital gap, and that candidates were far from proposing innovative strategies for establishing more direct communication with voters.

\section{Keywords:}

Digital and generational gap, election campaign, general elections of 2011 and 2015, Spain, Twitter.

Cómo citar este artículo:

Cervi, L. y Roca Trenchs, N. (2018). El uso de Twitter por parte de los principales candidatos en las campañas electorales para las elecciones generales españolas: 2011 y 2015. ¿iBrecha digital y generacional? Doxa Comunicación, 26, 99-126. 


\section{Introducción}

En España, el 67,6\% de la población estaba conectada a la Red en 2011: 31.574 .855 personas, según datos de Internet Live Stats, ${ }^{1}$ y en 2015 ya era el 80,4\% de la población la que tenía acceso a Internet, un total de 37.060.103 personas ${ }^{2}$. El EGM de octubre/noviembre de $2011^{3}$ indicaba que el 52,4\% de los usuarios utilizaba Internet para conectarse a las Redes Sociales, y en el EGM de octubre/noviembre de $2015^{4}$, ya era el $64,2 \%$ de la población. Los datos indican que los principales consumidores de Internet son personas de 25 a 44 años. Según Statista, Facebook es la red social con más usuarios: 483 millones en 2011 y 1.038 .000 en $2015^{5}$, mientras que Twitter pasó de los 117 en 2011 a los 305 usuarios activos en $2015^{6}$.

Twitter, aunque no sea la red más usada, sí es la que prefieren los actores políticos para ejecutar su campaña online y, sobre todo, para relacionarse con el electorado mediante nuevas fórmulas de comunicación (Abejón, Sastre y Linares, 2012; Casero-Ripollés, Miquel-Segarra y Alonso-Muñoz, 2016; Casero-Ripollés, Sintes-Olivella y Franch, 2017; Enli, 2017b; Enli y Skogerbø, 2013; Freelon y Karpf, 2015; Jungherr, 2014a; Jungherr, 2014b; Jungherr, 2016; Jürgens y Jungherr, 2016; Machado y Capdevila, 2016; Larsson y Moe, 2014; Skogerbø y Krumsvik, 2014; Vergeer, 2016; Zugasti y Sabés, 2015), además de las acciones propias de las campañas tradicionales que, sin duda, conviven con las online (Casero-Ripollés, Feenstra y Tormey, 2016; Enli, 2017a; Vergeer, 2016). "Digital media introduce certain novelties into electoral campaigns because they offer new tools for political communication”, según expresan Casero-Ripollés, Feenstra y Tormey (2016: 7), por lo que consideramos que Twitter es una poderosa herramienta para estrechar las relaciones entre los políticos y la ciudadanía.

Además, Twitter también ofrece "una gratuita, inmediata y masiva difusión, a la par que una interacción y un intercambio de información e ideas abierto y transparente” (Zugasti y Sabés, 2015: 163) y, según lo que escriben Rodríguez y Ureña (2012), supone un signo de modernidad, genera conversación con los ciudadanos y una sensación de comunidad, humaniza al candidato, se convierte en un termómetro social y transforma a los usuarios en líderes de opinión.

Y lo que es aún más importante, dada la rapidez con la que se distribuyen los contenidos que se publican y también el mayor acceso de la ciudadanía a Internet, los votantes vuelven a sentir interés por los asuntos políticos después de años sin mostrarlo (Abejón, Sastre y Linares, 2012; Barber, 1984; Davis, 2005; Enli, 2017a; Lilleker y Vedel, 2013; Swanson, 1995). Las sociedades más democratizadas se han vuelto a interesar por la política, factor que se ha desencadenado "[...] by the interest in online media and their decentralized nature that beholds the promise of empowerment”, según Carpentier (2016: 70); mientras que "digital tools enhance democracy by expanding citizen empowerment and engagement", después de que se haya producido una pérdida de los valores democráticos, según se rinde a la evidencia Persily (2017: 71).

\footnotetext{
1 http://www.internetlivestats.com

2 En 2017 ya había más de dos tercios de la población mundial usando Internet, lo que significa más de 3.570 millones de personas

3 http://www.aimc.es/a1mc-c0nt3nt/uploads/2012/04/internet311.pdf

4 http://www.aimc.es/almc-c0nt3nt/uploads/2015/12/internet315.pdf

5 https://es.statista.com/estadisticas/636622/facebook-numero-de-usuarios-activos-diarios-a-nivel-mundial-de-2011-a/

6 https://es.statista.com/estadisticas/513581/twitter-usuarios-mensualmente-activos-por-trimestres/
} 
Twitter, aunque fue una herramienta creada en el año 2006, tuvo su revulsivo en 2008, coincidiendo con la revolucionaria campaña electoral que hizo Barack Obama y que contra todo pronóstico (ya que no tenía el apoyo del establishment del partido) le permitió conseguir la presidencia de la Casa Blanca en Estados Unidos. Desde entonces, su campaña electoral ha sido ejemplo y modelo para los candidatos de la mayoría de países democráticos y no son pocos los estudios que se han realizado o que se han referido a ella, y tampoco sobre el hecho de que las redes sociales se hayan convertido en un referente para los candidatos a las elecciones de los países con una democracia estable (Beas, 2011; Casero-Ripollés, Feenstra y Tormey, 2016; Cervi y Roca, 2017; Costa, 2009; Enli, 2017b; Persily, 2017).

En esta investigación nos centramos en la campaña electoral para las elecciones generales españolas de 2011, que enfrentó a Mariano Rajoy (PP) y a Alfredo Pérez Rubalcaba (PSOE), los dos principales candidatos; y la del 2015, que enfrentó a Mariano Rajoy (PP), a Pedro Sánchez (PSOE), a Albert Rivera (Ciudadanos) y a Pablo Iglesias (Podemos), para analizar el uso cuantitativo y cualitativo que hicieron de su cuenta de Twitter. Hay que añadir que se han seleccionado los perfiles personales y no los perfiles de los partidos, dado el aumento del personalismo en las campañas electorales: "Social media such as Facebook and Twitter place the focus on the individual politician rather than on the political party, thereby expanding the political arena for increased personalized campaigning", tal y como observan Enli y Skogerbø (2013: 758). La investigación se ha hecho desde un enfoque nacional por lo que hay que recordar que el sistema político, electoral y de partidos en los que están suscritos los candidatos y su cultura política (Almond y Verba, 1963; Duverger, 1957; Kirchheimer, 1969; Lijphart, 1999; Lipset y Rokkan, 1967 y Sartori, 1980) pueden influir en la forma como afrontan las campañas electorales los sujetos políticos, ya que es posible que se establezcan límites a su desarrollo. Según la recopilación de Hallin y Mancini (2004), el sistema político español es considerado un modelo Pluralista Polarizado y se hace fundamental tenerlo en cuenta para saber los límites que se pueden dar en el uso de Internet, como también el hecho de que se trata de un sistema en el que ha habido una democratización tardía con largos períodos de autoritarismo. Además, vemos que aunque las campañas se están personalizando, los partidos aún tienen mucho poder en el desarrollo de las campañas, a la vez que el papel del voluntariado no es fundamental para enfocar la campaña electoral y los candidatos no necesitan pedir financiación porque las campañas se pagan con dinero público.

El Partido Popular ganó las elecciones de 2011 (que tuvieron una participación del 68,94\%) consiguiendo 186 representantes y el 44,63\% de los votos, de modo que Mariano Rajoy ganó con mayoría absoluta, mientras que el PSOE, con Alfredo Pérez Rubalcaba liderando la candidatura, consiguió 110 diputados con el 28,76\% de los votos.

Las elecciones generales del 20 de diciembre de 2015 (con un ligero aumento de la participación, el 69,97\%) supusieron un punto de inflexión en la historia de la política española. La campaña electoral enfrentó a los candidatos de la denominada “vieja política”, Mariano Rajoy (PP) y Pedro Sánchez (PSOE), con los representantes de la "nueva política”, Albert Rivera (Ciudadanos) y Pablo Iglesias (Podemos), a riesgo cierto de romper el bipartidismo que había predominado en la política española desde el restablecimiento de la democracia y durante la Transición, para convertirse en un sistema pluripartidista.

Aunque el Partido Popular fue el partido más votado consiguiendo el 28,71\% de los votos y 123 diputados, no tuvo suficiente fuerza para gobernar en solitario y tuvo que buscar un acuerdo con partidos que por primera vez entraban con 
fuerza al Congreso de los Diputados. Mariano Rajoy descartó un acuerdo con el otro gran partido del país, el PSOE, que consiguió el $22,01 \%$ de los votos y 90 diputados. Ciudadanos consiguió el 13,94\% de los votos y 40 diputados, y Podemos consiguió el 12,69\% de los votos y 42 diputados, pero finalmente no se encontró la fórmula de llegar a un acuerdo de gobierno estable y el candidato del Partido Popular, el más votado, convocó nuevos comicios que se celebraron el 26 de junio del año 2016.

Los resultados electorales fueron poco esclarecedores en un país donde se está empezando a producir una transformación de los partidos, pero, sin embargo, pusieron de relieve la voluntad de la ciudadanía por renovar el gobierno del Estado. Algo cambió, pues, en las elecciones que el entonces presidente del gobierno, Mariano Rajoy, convocó para el 20 de diciembre del 2015. La profunda crisis económica que ha azotado el país durante los últimos años y la aparición de numerosos casos de corrupción han propiciado una crisis social (aumentando las desigualdades entre ciudadanos) y política. La ciudadanía ya no se ha visto reflejada en los dos partidos preeminentes desde la Transición, cosa que ha dado lugar a la aparición de nuevos partidos en el tablero de juego, como Ciudadanos y Podemos, dispuestos a ser influyentes. Los candidatos (y los partidos que representaban) se dividieron los votos entre la ciudadanía según distintos perfiles. El estudio preelectoral del CIS de octubre del 2015 (el más próximo a las elecciones) ${ }^{7}$ indicaba que el Partido Popular tenía un perfil de votante de más de 65 años, sin estudios o con estudios de primaria, y un equilibrio de voto entre hombres y mujeres. El PSOE tenía un perfil de votantes sin estudios o con estudios de primaria, de más de 64 años, y escogido más por mujeres que por hombres. Ciudadanos tenía un perfil de votante con estudios de secundaria, formación profesional o estudios superiores, de entre 35 y 44 años, y más hombres que mujeres. Finalmente, Podemos tenía un perfil de votante con estudios de secundaria, formación profesional o estudios superiores, de entre 25 y 34 años, y más votado por hombres que por mujeres.

\subsection{Preguntas, objetivos e hipótesis}

A través de la comparación entre diferentes momentos y entre diferentes partidos, la investigación, pues, se plantea medir si se refleja una brecha generacional o digital entre los candidatos, partiendo de la base de tres preguntas preliminares.

Pregunta 1. ¿Cuánto usan Twitter los candidatos? Diferentes investigaciones ya se han ocupado del uso de las redes sociales por parte de los políticos españoles (Abejón, Sastre y Linares, 2012; Casero-Ripollés, Miquel-Segarra y Alonso-Muñoz, 2016; Casero-Ripollés, Sintes-Olivella y Franch, 2017; Cervi y Roca, 2017).

Objetivo 1. Determinar el uso cuantitativo de Twitter por parte de los candidatos.

Hipótesis 1. La hipótesis que queremos validar se basa en los perfiles de votantes y los perfiles de usuario de Twitter. Según Semiocast ${ }^{8}$, España se encontraba ya en 2011 en el lugar número 3 del ranking mundial de usuarios de Twitter más

\footnotetext{
7 http://www.cis.es/cis/opencm/ES/1_encuestas/estudios/listaMuestras.jsp?estudio=14245

8 https://semiocast.com/
} 
activos, detrás de los Países Bajos y Japón, y el perfil del usuario, comprobado tanto por ONTSI ${ }^{9}$ como por Statista $^{10}$, en ambos años queda sustancialmente sin variaciones y se caracteriza por ser la red preferida de los hombres de entre $35 \mathrm{y}$ 44 años. Un $90 \%$ tiene entre 24 y 54 años -eso significa que tanto los millenials como los más mayores quedan, de hecho, excluidos- y en más de un $75 \%$ de los casos tienen estudios superiores. Si cruzamos estos datos con el anteriormente mencionado perfil de votante de cada partido delineado por el CIS, deberíamos suponer que respectivamente Ciudadanos, con un perfil de votante de entre 35 y 44 años, y Podemos, con un perfil de votante de entre 25 y 34 años, deberían ser los partidos más activos en Twitter.

Pregunta 2. ¿Cómo usan Twitter los candidatos?, es decir, ¿lo usan como un medio más de forma unilateral para difundir información sobre su campaña o lo aprovechan para generar una nueva relación y nuevas formas de interacción con los ciudadanos?

Como profundizaremos en el apartado metodológico, la Red ofrece muchas posibilidades, pero esto no significa que el emisor quiera/pueda aprovecharlas todas. Concretamente, tal y como señalan, entre otros, Lilleker y Vedel (2013), Twitter puede ser usada a diferentes niveles: información, deliberación (discusión) y/o movilización para la participación.

Objetivo 2. Determinar cualitativamente como utilizan Twitter los candidatos.

Hipótesis 2. Si es cierto que mientras los partidos "tradicionales" tienden a situar la participación en una posición más periférica dentro de la agenda pública, atribuyendo a la participación ciudadana un valor meramente informativo o consultivo (Font y Blanco 2005), tanto Podemos, que la concibe como un complemento necesario a las instituciones representativas para enriquecer el proceso de toma de decisiones, como Ciudadanos, que hace de un nuevo diálogo con los ciudadanos su bandera política, otorgan a la participación una necesaria centralidad. Entonces, estas diferentes actitudes se deberían ver reflejadas en el uso que los candidatos hacen de Twitter. En otras palabras, esperamos que los partidos más "jóvenes" hagan un uso más "completo" de la Red aprovechando todas las oportunidades que esta les brinda para fomentar la participación.

Pregunta 3. ¿Cómo impacta la presencia de los candidatos denominados de la nueva política sobre los demás en el uso de Twitter?. Si, como demuestra Talbot (2008), el uso masivo de Internet por parte del equipo Obama de alguna forma obligó a Kerry a entrar en la "arena digital", ¿podemos suponer un efecto contagio parecido en España?

Objetivo 3. Determinar si los candidatos de la nueva política arrastran a los candidatos de la "vieja política" a usar Twitter.

Hipótesis 3. Pablo Iglesias y Albert Rivera ya estaban activos en Twitter desde 2010, mientras que tanto Rubalcaba como Rajoy se unieron a la red solo meses o incluso días antes del comienzo de la campaña de 2011; por lo tanto, si los "nuevos" políticos ya estaban activos en Twitter y ya tenían generada una cierta relación bidireccional con la ciudadanía, consideramos que los demás, es decir, los candidatos de los partidos "tradicionales", se hayan visto arrastrados a usar más y mejor esta Red. Puede, diciéndolo gramscianamente, que si Twitter se transforma en medio hegemónico, todos los actores se sentirán de alguna forma obligados a sumarse.

9 http://www.ontsi.red.es/ontsi/

10 https://es.statista.com/estadisticas/513581/twitter-usuarios-mensualmente-activos-por-trimestres/ 


\section{Metodología}

La investigación parte de una metodología comparativa que se aborda desde la perspectiva teórica y práctica. Hoy existen muy valiosas aportaciones sobre el método comparativo de autores como Hallin y Mancini (2004), Kluver et al. (2007), Lijphart (1971) Lilleker, et al. (2011), Negrine y Papathanassopoulos (1996), Sartori (1970), Schneider y Foot (2002), Vergeer (2016), Vergeer y Cunha (2009), Vergeer et al. (2013), que permiten entender de una forma más global las estrategias de los candidatos durante las campañas electorales. Así, estamos de acuerdo con Enli (2017a), Larsson y Moe (2014) o Strömbäck y Kiousis (2014) cuando subrayan que aún no hay suficientes estudios internacionales y que tendrían que potenciarse. Además, también hay que tener en cuenta las teorías que plantean Anduiza (2009), Enli y Skogerbø (2013), Gibson y Römmele (2007), Hallin y Mancini (2004), Kaid y Holtz-Bacha (1995), Kalnes (2009), Lilleker y Vedel (2013), Negrine y Papathanassopoulos (1996), Norris (2000), Plasser y Plasser (2002), Scammell (1997), Strömbäck y Kiousis (2014), Swanson y Mancini (1996), o Vergeer (2016), sobre el hecho de que no existe una teoría unánime que explique las transformaciones que sufren las campañas electorales.

La investigación también se basa en un análisis que combina los datos cuantitativos y cualitativos. Los datos objeto de análisis son las publicaciones hechas en Twitter por los candidatos: Pedro Sánchez (PSOE), Albert Rivera (Ciudadanos) y Pablo Iglesias (Podemos) durante el período de campaña electoral del 2015 (4-18 de diciembre de 2015), y Mariano Rajoy (PP) y Alfredo Pérez Rubalcaba (PSOE) durante la campaña electoral de 2011 (4-18 de noviembre de 2011). Cabe insistir en que en esta investigación el enfoque es sobre el candidato, es decir, nos centramos en cuánto y cómo usan Twitter los candidatos, dejando de lado el impacto que su uso puede tener en los usuarios, que podría ser sujeto de otra investigación.

Con el análisis cuantitativo hemos querido evaluar cuánto se usa Twitter; por ello, hemos medido el número de tuits, retuits y respuestas que hicieron los candidatos durante el período de campaña electoral. Los datos se han recuperado de la web www.tweetstats.com que almacena todos los datos de forma mecánica y permite que puedan recuperarse mucho tiempo después. Además, se han recogido manualmente el número de seguidores, personas a quienes siguen los candidatos, y los "me gusta".

Para observar cómo los candidatos usan esta red, es decir, qué tipo de interacción propician con sus votantes, hemos aplicado un análisis cualitativo. Dicho análisis se plantea con un sistema de recogida de datos que consiste en la confección de un cuestionario compuesto por una serie de preguntas cuya función es la de determinar la forma en la cual los candidatos se comunican con el electorado, es decir, si lo hacen de una forma más bien jerárquica o de una forma más cercana y horizontal. Así, adoptamos y adaptamos los tres niveles de comunicación que plantean Lilleker y Vedel (2013): información, deliberación (discusión) y movilización para la participación, para categorizar las preguntas.

Lilleker y Vedel (2013) consideran que existen tres niveles de posible interacción: el primero, el más básico, el de información, donde el usuario, en nuestro caso el candidato, usa las redes sociales sustancialmente como un "antiguo" medio para vehicular información, sin propiciar ninguna forma de interacción con los demás; en el nivel intermedio encontramos la deliberación, que, como sugiere la palabra misma, favorece un intercambio bilateral de opiniones mediante la petición más o menos abierta de un feedback; y finalmente, en el nivel más alto, encontramos la movilización y participación 
ciudadana, en el que el candidato incita abiertamente a los ciudadanos a participar en la campaña, ya sea compartiendo o creando contenido, actuando como voluntarios, etc.

Las preguntas de nuestro cuestionario reflejan estos tres niveles. En el nivel "información”, caracterizado como un sistema unilateral de comunicación, los electores, en definitiva, se convierten en simples espectadores de las campañas electorales. Las preguntas que se plantean parten de la biografía (vida personal, carrera académica, experiencia profesional, aficiones, etc.), actos de campaña (calendario, dónde y cómo votar, mítines, reuniones), programa electoral (propuestas, críticas al rival), y contenido audiovisual (fotografías, vídeos, infografías, etc.). En cambio, en la "deliberación” ya existe cierto contacto entre los actores políticos y los votantes, un feedback que permite un intercambio bilateral de opiniones. Así, nos planteamos si los candidatos se implicaron activamente en el proceso de diálogo con la ciudadanía y respondieron a sus preguntas, si los usuarios generaron debate y no solamente dieron su soporte al candidato, y si el candidato ejecutó algún otro tipo de iniciativas para promover la deliberación. Finalmente, para evaluar el nivel más amplio de comunicación, la "participación ciudadana", preguntamos si el candidato pidió el voto, si promovió el voluntariado, si pidió donaciones para pagar la campaña electoral, si alentó a sus simpatizantes a retuitear los contenidos publicados en su perfil, o si el candidato llevó a cabo otras iniciativas relacionadas con el fomento de la participación.

Como hemos mencionado, el análisis se plantea con un sistema de recogida de datos que consiste en la confección de un cuestionario compuesto por una serie de preguntas contestables con un sí o con un no. Para procesar los datos y darles un valor empírico, se asigna un valor de 1 a las respuestas afirmativas y de 0 a las negativas. Este método parte de la propuesta empleada por Vergeer y Cunha (2009) y ofrece la posibilidad de medir empíricamente cada categoría mediante una hoja de cálculo, que nos permite llevar a cabo el ejercicio comparativo sobre la calidad del uso de Twitter por parte de los candidatos. Para ello, también nos hemos centrado en otras investigaciones, como las de Cervi y Roca (2016), Kluver et al. (2007), Lilleker et al. (2011), Lilleker y Vedel (2013), Schneider y Foot (2002) o Vergeer et al. (2013).

Tal y como se muestra en el cuadro 1, se plantearon en total 17 preguntas, de las cuales 9 referentes al nivel “información”, 3 al nivel “deliberación” y 5, al nivel "participación”.

Cuadro 1: Parámetros para analizar el nivel “información”, “deliberación” y “participación”.

\begin{tabular}{|c|c|c|c|c|c|}
\hline INFORMACIÓN & Sí (1) / No (0) & DELIBERACIÓN & Sí (1) / No (0) & PARTICIPACIÓN & Sí (1) / No (0) \\
\hline $\begin{array}{l}\text { 1. ¿El candidato completa el } \\
\text { espacio que ofrece Twitter para } \\
\text { definirse? }\end{array}$ & & $\begin{array}{l}\text { 1. ¿El candidato se implica activamen- } \\
\text { te en el proceso de diálogo con la ciu- } \\
\text { dadanía? ¿Comenta las publicaciones } \\
\text { que hacen los usuarios? ¿Responde } \\
\text { preguntas? }\end{array}$ & & 1. ¿El candidato pide el voto? & \\
\hline $\begin{array}{l}\text { 2. ¿El candidato ofrece detalles } \\
\text { de su vida personal y familiar? } \\
\text { (estado civil, aficiones, carrera } \\
\text { académica, experiencia } \\
\text { profesional, etc.) }\end{array}$ & & $\begin{array}{l}\text { 2. ¿A partir de las publicaciones del } \\
\text { candidato, los usuarios generan deba- } \\
\text { tes (no solamente le dan su soporte)? }\end{array}$ & & $\begin{array}{l}\text { 2. ¿El candidato pide que los } \\
\text { electores se hagan voluntarios } \\
\text { durante la campaña y partici- } \\
\text { pen en las actividades que se } \\
\text { promueven? }\end{array}$ & \\
\hline $\begin{array}{l}\text { 3. ¿El candidato publica los actos } \\
\text { de campaña (mítines, debates, } \\
\text { reuniones y encuentros) a los que } \\
\text { asiste? }\end{array}$ & & $\begin{array}{l}\text { 3. ¿El candidato ejecuta otras iniciati- } \\
\text { vas para promover la deliberación? }\end{array}$ & & $\begin{array}{l}\text { 3. ¿El candidato pide que el } \\
\text { usuario haga un donativo para } \\
\text { pagar la campaña electoral? }\end{array}$ & \\
\hline
\end{tabular}


El uso de Twitter por parte de los principales candidatos en las campañas electorales para las elecciones...

\begin{tabular}{|c|c|c|c|c|}
\hline $\begin{array}{l}\text { 4. ¿El candidato anuncia con } \\
\text { antelación los actos de campaña a } \\
\text { los que tiene previsto asistir? }\end{array}$ & & & $\begin{array}{l}\text { 4. } i \text { El candidato pide a sus } \\
\text { seguidores que retuiteen los } \\
\text { contenidos que publica en su } \\
\text { perfil? }\end{array}$ & \\
\hline $\begin{array}{l}\text { 5. ¿El candidato informa sobre } \\
\text { el proceso de voto (dónde votar, } \\
\text { cómo votar)? }\end{array}$ & & & $\begin{array}{l}\text { 5. ¿El candidato ejecuta otras } \\
\text { iniciativas para promover la } \\
\text { participación? }\end{array}$ & \\
\hline $\begin{array}{l}\text { 6. ¿El candidato hace } \\
\text { publicaciones relacionadas con } \\
\text { temas como su ideología o el } \\
\text { programa electoral? }\end{array}$ & & & & \\
\hline $\begin{array}{l}\text { 7. iEl candidato compara sus } \\
\text { propuestas con las de sus } \\
\text { oponentes? }\end{array}$ & & & & \\
\hline $\begin{array}{l}\text { 8. ¿El candidato critica a sus } \\
\text { oponentes? }\end{array}$ & & & & \\
\hline $\begin{array}{l}\text { 9. iEl candidato publica } \\
\text { documentos multimedia? }\end{array}$ & & & & \\
\hline 9.1. ¿Publica fotografías? & & & & \\
\hline 9.2. ¿Publica vídeos? & & & & \\
\hline $\begin{array}{l}\text { 9.3. ¿Publica documentos de } \\
\text { audio? }\end{array}$ & & & & \\
\hline $\begin{array}{l}\text { 9.4. iPublica otro tipo de } \\
\text { documentos multimedia: } \\
\text { infografías, carteles, pósteres, etc.? }\end{array}$ & & & & \\
\hline & TOTAL & TOTAL & & TOTAL \\
\hline & 9 & 3 & & 5 \\
\hline & TOTAL SÍ & TOTAL SÍ & & TOTAL S \\
\hline & TOTAL \% & TOTAL \% & & TOTAL \% \\
\hline
\end{tabular}

Fuente: elaboración propia

\section{Resultados}

\subsection{Campaña electoral de 2011}

En la campaña electoral de 2011 los candidatos de los principales partidos fueron Mariano Rajoy por el Partido Popular y Alfredo Pérez Rubalcaba por el Partido Socialista Obrero Español. El primero, empezó a utilizar Twitter el mes de septiembre de 2011 bajo el perfil @marianorajoy, tan solo dos meses antes del día de las elecciones, y se definía así: “Soy el presidente del partido popular y candidato a la presidencia del Gobierno de España. Bienvenido a mi Twitter, donde me acompaña mi equipo". Aunque no firmaba siempre sus tuits, cuando lo hacía los firmaba con las iniciales MR y añadía un enlace a su página web. Su primer mensaje fue: "En el AVE llegando a Barcelona. A pesar de mi inexperiencia estreno con ilusión mi Twitter en el que cuento con todos. MR”. Y solo en cuatro días ya le seguían 30.000 usuarios. 
El candidato socialista, en cambio, se unió a Twitter (@conRubalcaba) tan solo dos meses antes que su principal rival en las elecciones generales de 2011, concretamente, en julio de 2011, y su mensaje de presentación fue: "Hola, este es el Twitter del equipo electoral de Rubalcaba, -seguido de- Estaremos aquí para escuchar vuestras sugerencias y críticas, y para escuchar". Inicialmente, Rubalcaba fue muy criticado porque su perfil era poco personal, ya que al no estar acostumbrado al uso de las Redes Sociales (no usaba ningún smartphone), le acompañaba un numeroso equipo de personas que gestionaban su perfil.

\subsubsection{Análisis cuantitativo}

Tal y como podemos apreciar en el cuadro 2, Mariano Rajoy con un total de 112.176 seguidores, 33.256 de los cuales ganados en campaña, superó en número de seguidores a su principal rival, que tenía 77.751 seguidores y ganó 26.473 durante el período electoral. No obstante, fue Rubalcaba el candidato que seguía a más personas al final de la campaña electoral, un total de 7.354; mientras que Rajoy seguía a 2.657. Durante el período electoral, sin embargo, fue el candidato popular quien empezó a seguir a más personas: 152 frente a las 129 del candidato socialista.

Cuadro 2: Número de seguidores y siguiendo a Twitter por parte de cada candidato en 2011

\begin{tabular}{|c|c|c|c|c|c|c|}
\hline & $\begin{array}{c}\text { Seguidores } \\
\text { inicio campaña }\end{array}$ & $\begin{array}{c}\text { Seguidores fin } \\
\text { campaña }\end{array}$ & Diferencial & $\begin{array}{c}\text { Siguiendo inicio } \\
\text { campaña }\end{array}$ & $\begin{array}{c}\text { Siguiendo final } \\
\text { de campaña }\end{array}$ & Diferencial \\
\hline Mariano Rajoy & 78.920 & 112.176 & $\mathbf{3 3 . 2 5 6}$ & 2.505 & 2.657 & $\mathbf{1 5 2}$ \\
\hline Alfredo Pérez Rubalcaba & 50.678 & 77.151 & $\mathbf{2 6 . 4 7 3}$ & 7.225 & 7.354 & \\
\hline
\end{tabular}

Fuente: elaboración propia

El cuadro 3 nos muestra la cantidad de tuits, retuits y respuestas, evidenciando que Alfredo Pérez Rubalcaba fue el candidato que más tuiteó y retuiteó, mientras que Rajoy respondió 575 tuits, 66 más que Rubalcaba.

Cuadro 3: Número de tuits, retuits y respuestas en 2011

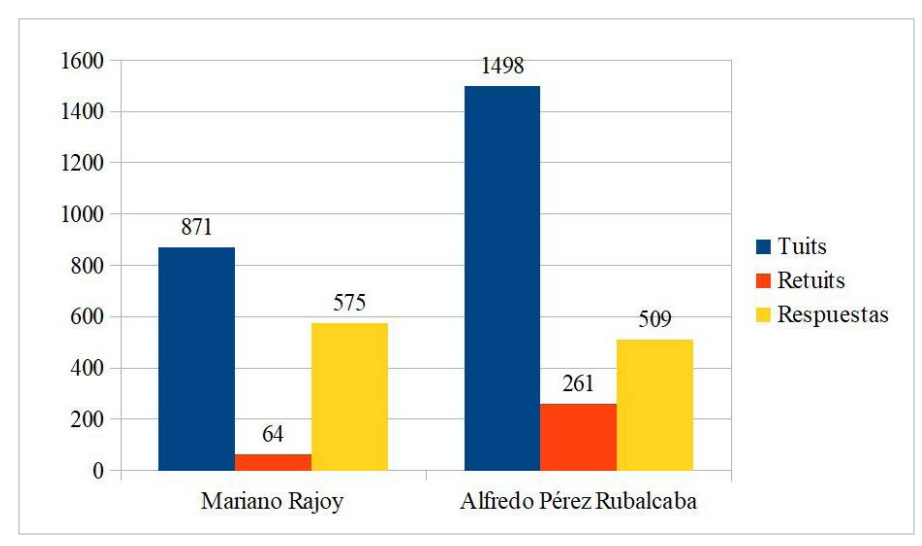

Fuente: elaboración propia partiendo de Tweetstats 


\subsubsection{Análisis cualitativo}

Si nos centramos en el tipo de uso que se le dio a Twitter, podemos observar que Mariano Rajoy usó la red para difundir informaciones, como las publicaciones de los mítines, reuniones y debates en los que participaba -y que acompañaba con fotografías, vídeos y documentos de audio (en el caso de que le hicieran entrevistas en la radio)-, y para dar a conocer las principales propuestas de su programa electoral.

Los datos de la investigación, que se pueden ver en el cuadro 4, nos muestran que Mariano Rajoy se implicó activamente en el diálogo, por lo que se estableció un intercambio de información con sus seguidores. Los seguidores de Rajoy se dirigían a él para hacerle preguntas y a la vez le mostraban su fidelidad, aunque también había quienes aprovechaban para criticar sus políticas.

Una de las iniciativas que se ejecutaron para fomentar la deliberación fue una entrevista a través de Twitter. Los seguidores podían hacerle preguntas al candidato bajo la etiqueta \#rajoyresponde. De las 750 preguntas que se plantearon, el equipo de Rajoy contestó 6.

Dicho esto, y siendo una realidad que en el análisis se pudieron contestar afirmativamente todas las preguntas relativas a la deliberación, queremos señalar que muchas de las preguntas que Rajoy respondió se remitían al programa electoral, por lo que no existió un feedback auténtico ni un diálogo abierto, tal y como se muestra en la siguiente imagen:

El candidato popular no dudó en pedir el voto a sus seguidores, pero no hubo ninguna acción para llamar a la colaboración, ni se pidieron donativos.

marianorajoy Mariano Rajoy Erey

@FernandoGarzo,@misterempresa, le invitamos a conocer la medida 3 de la página 40 \#ProgramaPP ow.ly/7h84l Le gustará. Gracias.

Cuadro 4: Nivel de “información”, “deliberación” y “participación” por parte de Rajoy

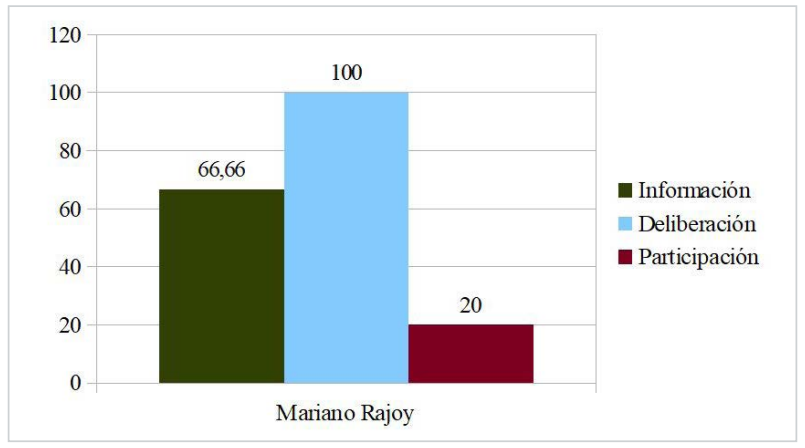

Fuente: elaboración propia 
En el cuadro 5 se pueden ver los resultados del uso cualitativo que hizo de Twitter Alfredo Pérez Rubalcaba. El candidato socialista aprovechó esta herramienta para hacer públicos los mítines, reuniones y otras actividades relacionadas con la campaña electoral, a la vez que también publicó fotografías, vídeos y documentos de audio. Rubalcaba también criticó las propuestas de Rajoy y dio a conocer las suyas propias. El candidato socialista también publicó una agenda en la que difundía las actividades de campaña y utilizaba la etiqueta \#MitinsEnRuta para atraer la atención de su electorado.

Rubalcaba debatió con la ciudadanía a través de la propuesta \#yorespondo, en la que sus seguidores podían formularle preguntas. De las más de 800 que recibió, el equipo socialista respondió 70 vía streaming. El candidato socialista también respondió otras preguntas, como las que se ven en la siguiente imagen:

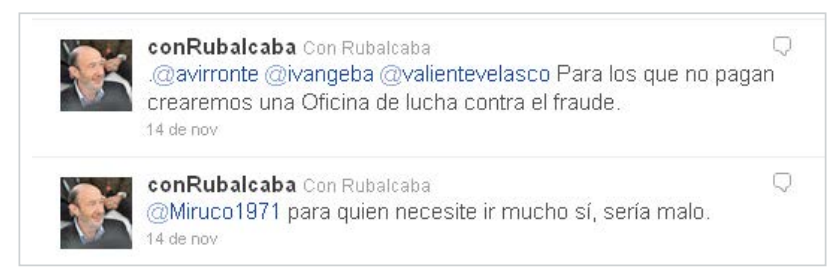

Además, Rubalcaba también hizo llegar preguntas al líder del PP, unas preguntas que nunca obtuvieron respuesta por parte de su principal oponente.

El candidato socialista pedía a sus seguidores que acudiesen a las urnas, pero más allá de reclamar el voto, el candidato socialista pidió la participación del electorado para que este le diese ideas y sugerencias para el debate televisivo mediante la etiqueta \#undebatedecisivo: "Faltan 24 horas para el debate. Estoy ultimándolo con mi equipo. Me gustaría que me mandarais ideas y sugerencias”.

Otra propuesta de Rubalcaba fue la “Twitter entrevista”, que tuvo lugar el 11 de noviembre. Antoni Gutiérrez-Rubí, asesor de comunicación, le planteó al candidato una serie de preguntas, cada una de ellas debía responderla en 9 segundos. La "Twitter entrevista" fue publicada posteriormente en el canal de YouTube.

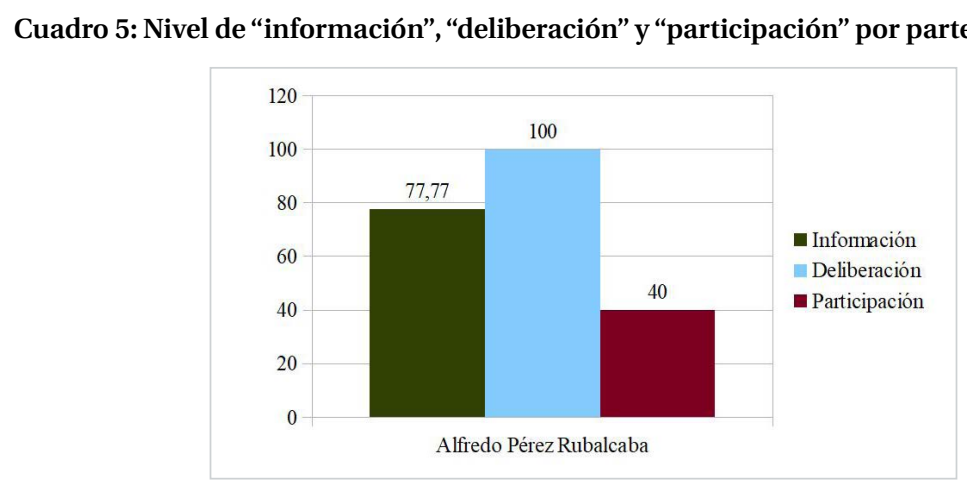

Fuente: elaboración propia 
El uso de Twitter por parte de los principales candidatos en las campañas electorales para las elecciones...

\subsection{Campaña electoral de 2015}

La campaña de 2015 se caracterizó por la aparición de dos nuevos actores políticos: Pablo Iglesias, líder y candidato de Podemos, y Albert Rivera, candidato de Ciudadanos. El PP, por su parte, volvió a presentar a Mariano Rajoy y el PSOE presentó a Pedro Sánchez, sustituyendo a Alfredo Pérez Rubalcaba.

\subsubsection{Análisis cuantitativo}

El cuadro 6 nos muestra que Pablo Iglesias fue el candidato que más seguidores tenía al final de la campaña electoral de 2015, 1.408.513, mientras que ganó 63.149 seguidores durante la campaña. Mariano Rajoy tenía 1.043.083 seguidores al final de la campaña electoral y fue el segundo candidato que más ganó, 37.809. El candidato socialista, Pedro Sánchez, fue el que menos seguidores tenía, 233.750, y el que menos ganó, 21.482.

Asimismo, fue Mariano Rajoy, no solo el candidato que seguía a más personas, un total de 10.699 el último día de campaña, sino el que más personas empezó a seguir durante los días que duró la misma, 225 personas. Pedro Sánchez solo empezó a seguir a 20 personas; Albert Rivera a 14; y Pablo Iglesias solamente a 5 personas, mientras que seguía a 1.894 a final de campaña.

Cuadro 6: Número de seguidores y siguiendo a Twitter por parte de cada candidato en 2015

\begin{tabular}{|c|c|c|c|c|c|c|}
\hline & $\begin{array}{l}\text { Seguidores inicio } \\
\text { campaña }\end{array}$ & $\begin{array}{l}\text { Seguidores fin } \\
\text { campaña }\end{array}$ & Diferencial & $\begin{array}{l}\text { Siguiendo inicio } \\
\text { campaña }\end{array}$ & $\begin{array}{l}\text { Siguiendo final de } \\
\text { campaña }\end{array}$ & Diferencial \\
\hline Mariano Rajoy & 1.005 .274 & 1.043 .083 & 37.809 & 10.474 & 10.699 & 225 \\
\hline Pedro Sánchez & 212.268 & 233.750 & 21.482 & 5.799 & 5.819 & 20 \\
\hline Albert Rivera & 410.555 & 443.581 & 33.026 & 1.962 & 1.976 & 14 \\
\hline Pablo Iglesias & 1.345 .364 & 1.408 .513 & 63.149 & 1.889 & 1.894 & 5 \\
\hline
\end{tabular}

Fuente: elaboración propia mediante Tweetstats

Según los datos que se desprenden del cuadro 7, Mariano Rajoy fue el candidato que más tuiteó durante la campaña electoral de 2015, seguido de Pedro Sánchez, Albert Rivera y Pablo Iglesias, que fue el candidato que menos tuits publicó. Rajoy también fue el candidato que hizo más retuits y dio más “me gusta”. Albert Rivera, en cambio, fue el candidato que más respuestas dio, un total de 21, mientras que Iglesias solo respondió 2; Mariano Rajoy, 1; y Pedro Sánchez, ninguna. 
Cuadro 7: Número de tuits, retuits, respuestas y “me gusta” en 2015

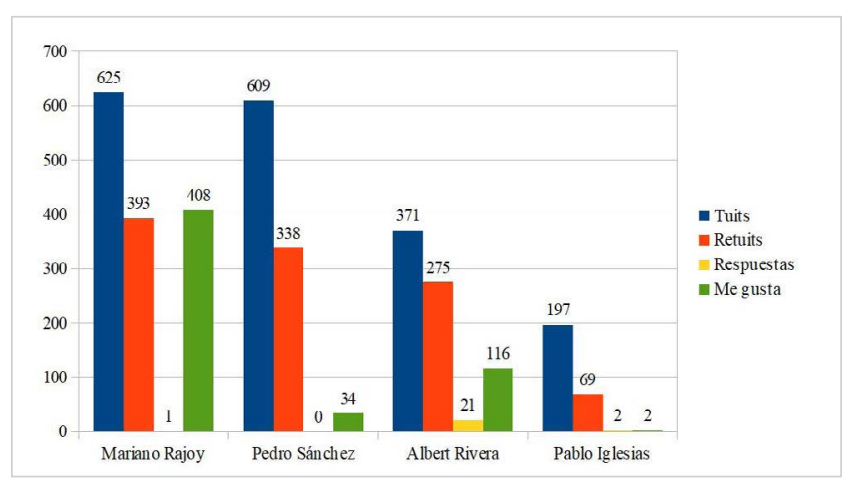

Fuente: elaboración propia partiendo de Tweetstats

\subsubsection{Análisis cuantitativo}

Mariano Rajoy, como anteriormente hemos mencionado, fue el único que repitió como candidato en las elecciones de 2015. Cuatro años después, se definía en Twitter como: "Presidente del Gobierno y del @Ppopular. Candidato al \#20D. Casado y padre de dos hijos. Trabajo por una España mejor, me acompaña mi equipo. Únete”. No obstante, no dio a conocer más detalles de su vida personal: carrera profesional y/o académica, ni publicó fotografías o vídeos junto a su familia.

Durante la campaña electoral, el candidato popular difundió su programa electoral y profundizó sobre algunas de sus propuestas de gobierno prometiendo estabilidad, crecimiento y empleo, financiación autonómica, ley de dependencia, la protección de la infancia o la lucha contra el terrorismo, etc., y acompañaba sus tuits con la etiqueta \#EspañaEnSerio. Mariano Rajoy también aprovechó Twitter para promocionar las actividades del gobierno en funciones y explicar qué medidas se habían tomado los últimos cuatro años de gobierno popular, y para publicar algunas de las actividades incluidas en su agenda y convocar así a sus simpatizantes, a la vez que las retransmitía en directo por streaming.

Mariano Rajoy Brey @marianorajoy - 23 h

Hay que estar juntos en los grandes retos como normas

constitucionales, defensa de \#España y lucha contra el terrorismo

\#EspañaEnSerio

Durante el cara a cara que se retransmitió en televisión entre Mariano Rajoy y Pedro Sánchez, el equipo de campaña popular publicó tuits atacando al antiguo gobierno del PSOE, diciendo que había hecho una gestión nefasta de la crisis, que nunca se reconoció la precaria situación actual, y añadió que la ciudadanía no podía fiarse del PSOE. Rajoy también se dirigió al candidato socialista con la etiqueta \#PedroYaNoCuela mediante la que se escribían críticas al candidato. El equipo de campaña también creó un comparador de programas electorales, a la vez que explicó algunas diferencias respeto al del PSOE, como, por ejemplo, que el PP estaba comprometido con las pensiones mientras que el PSOE las había congelado. 
Durante la campaña electoral, el equipo del candidato popular recurrió a fotografías, vídeos y carteles para difundir la candidatura. Por ejemplo, se hicieron vídeos de resumen de la actividad semanal del candidato, a la vez que se explicaban textualmente las principales propuestas o acciones de gobierno ejecutadas los últimos cuatro años de gobierno, como muestra la imagen siguiente:

Tal y como muestra el cuadro 8, Mariano Rajoy rebajó el nivel de diálogo con los ciudadanos, aunque sí agradeció el apoyo que recibía de sus simpatizantes y aseguraba que leía todos los tuits que se publicaban en su perfil, por lo general, no contestó las preguntas que se le hicieron a través de esta red durante la campaña electoral.

En lo referente a la movilización y participación ciudadana, Rajoy pidió el voto de sus seguidores y simpatizantes, a la vez que acompañaba algunos tuits con la etiqueta \#VotaPP.

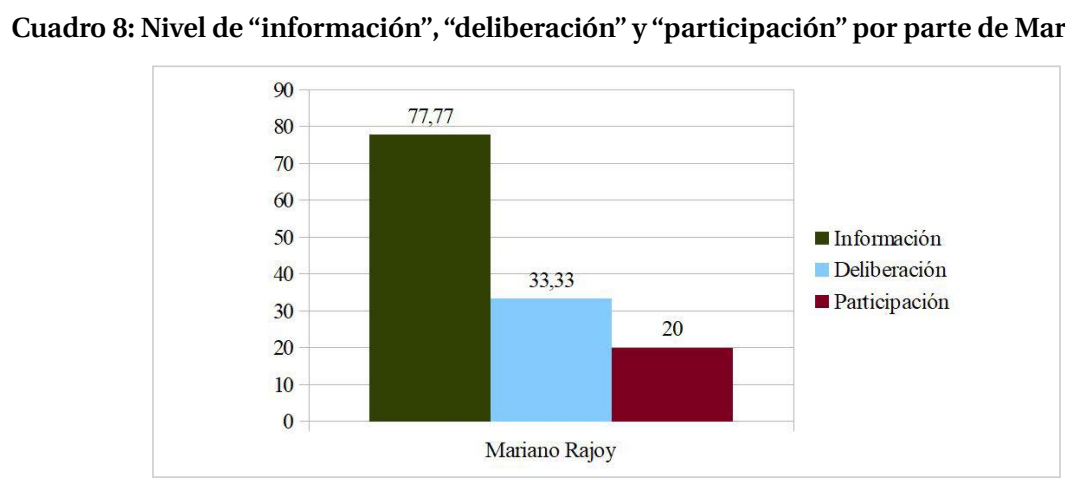

Fuente: elaboración propia

Pedro Sánchez Castejón (@sanchezcastejon) se unió a Twitter en agosto de 2009 definiéndose así durante la campaña electoral: “Padre. Doctor en economía. Candidato socialista a la presidencia del Gobierno. Secretario General del @PSOE. Trabajo en equipo, también aquí”.

El nuevo candidato socialista, que sustituía a Alfredo Pérez Rubalcaba en el liderazgo del partido y que representaba una renovación interna, publicó mítines, entrevistas y distintas actividades en las que participaba. Y aunque no daba a conocer su agenda diaria, sí que informaba con antelación sobre algunos de los actos a los que asistiría. Todas las publicaciones iban acompañadas de fotografías y vídeos, a la vez que también se publicaban documentos de audio cuando lo entrevistaban en la radio.

Sánchez no dio a conocer más detalles de su vida personal que su profesión y su situación familiar en la parte destinada a biografía, pero el último día de campaña sí tuvo unas palabras de agradecimiento para su familia.

Durante la campaña electoral, el candidato se concentró en transmitir sus principales propuestas de gobierno: la derogación de la reforma laboral, ley de dependencia, energía, trabajo, etc. Pedro Sánchez también publicó un vídeo en el que se comprometía con sus simpatizantes. Finalmente, el candidato socialista también criticó a sus principales rivales y sus propuestas. 
Tal y como vemos en el cuadro 9, el candidato socialista promovió la deliberación con la ciudadanía. Sánchez Castejón impulsó una iniciativa en la que sus seguidores podían proponer una serie de preguntas que el candidato posteriormente tuvo que responder a través de un vídeo de unos seis minutos de duración, y en el que prometía abrir las puertas de la Moncloa, haciéndola más transparente. El candidato también agradeció las muestras de apoyo.

El candidato socialista aprovechó Twitter para pedir el voto a sus simpatizantes, tal y como se muestra en la imagen siguiente:

Finalmente, Sánchez Castejón no sacó todo el provecho de esta herramienta para comunicarse de una forma más horizontal con el electorado y hacerle sentir partícipe de la campaña electoral.

Cuadro 8: Nivel de “información”, “deliberación” y "participación” por parte de Pedro Sánchez

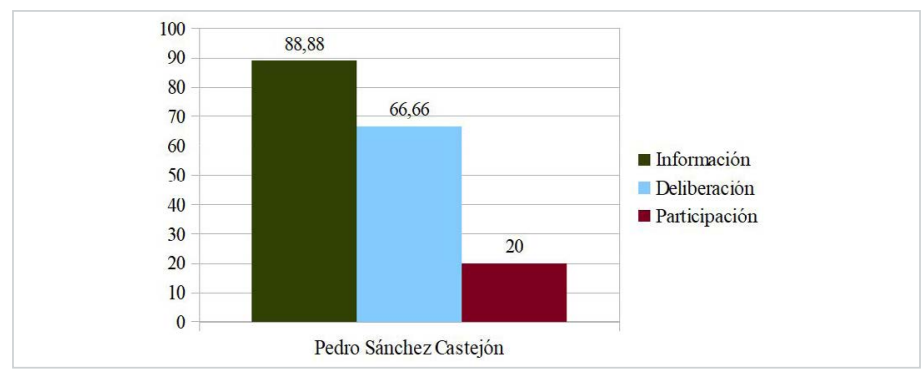

Fuente: elaboración propia

Albert Rivera (@Albert_Rivera) se unió a Twitter en enero de 2010 y se definía así durante la campaña electoral: “Perfil oficial de Albert Rivera Díaz. Presidente de C's y candidato a la presidencia del gobierno. Imposible es sólo una opinión”.

El candidato de Ciudadanos aprovechó para promocionar su figura pública pero no dio detalles de su vida personal, ni de su carrera profesional o académica. Así, el candidato de C's se concentró en la campaña electoral y en su timeline; publicaba con antelación los actos de campaña en los que iba a participar con carteles que anunciaban la hora y el lugar, así como también se publicaban fotos de los mítines.

Albert Rivera también difundió y defendió su programa electoral, en el que entre otras propuestas se quería crear una caja común para las autonomías con el fin de financiar la sanidad y la educación. El candidato aclaró que no iba a pactar con partidos separatistas ni con Podemos, que defendía un referéndum para Cataluña. Su objetivo era la regeneración de un proyecto común para España, pero no publicó el programa electoral entero y sus seguidores no pudieron consultar propuestas más detalladas. Rivera también defendió la oportunidad de ilusionarse con España, tal y como vemos en la siguiente imagen: 


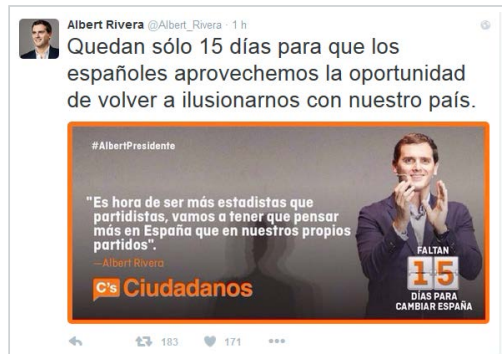

El candidato de Ciudadanos se centró en la promoción de su figura pero también criticó un posible pacto denominado "PPSOE".

Rivera utilizó distintos lemas durante la campaña electoral: "Vota con ilusión” o \#AdelanteCiudadanos.

Tal y como vemos en el cuadro 9, en lo referente a la deliberación, el candidato de Ciudadanos estuvo abierto a intercambiar impresiones con sus simpatizantes y respondía a algunas de las interpelaciones que le hacían.

Finalmente, Rivera no fomentó activamente la movilización y participación ciudadana, y se limitó a pedir el voto para el partido que presidía.

Cuadro 9: Nivel de “información”, “deliberación” y "participación” por parte de Albert Rivera

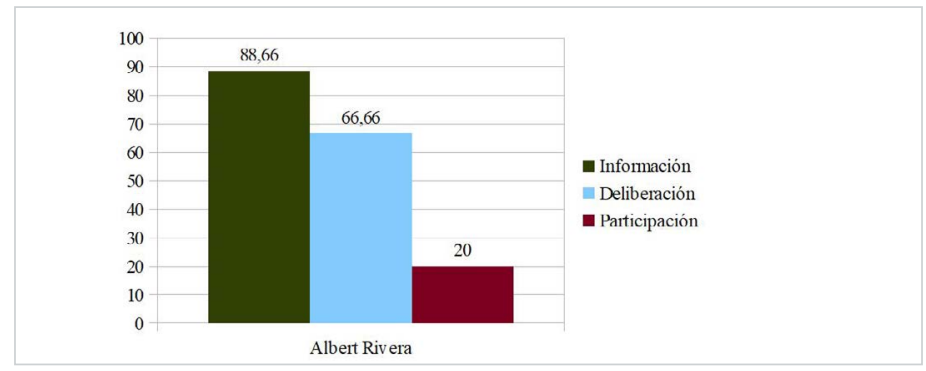

Fuente: elaboración propia

Pablo Iglesias (@Pablo_Iglesias_) se unió a Twitter en junio de 2010. El candidato de Podemos se definía de la siguiente manera: "Secretario general @ahorapodemos y candidato a la presidencia del gobierno. Profesor honorífico de la UCM. Llegó el momento para el que nacimos. ¡Ahora Podemos!” Los electores no obtuvieron más información sobre la vida personal y profesional de Iglesias, pero este sí publicó una foto de cuando era pequeño.

El cuadro 10 da respuesta al uso cualitativo de Pablo Iglesias en Twitter. El candidato de Podemos usó esta herramienta para informar, sobre todo, de los actos de campaña en los que participaba: mítines, reuniones, entrevistas, etc. (que anunciaba con antelación) y no tanto para difundir sus propuestas de gobierno. Iglesias no publicó el programa electoral, aunque sí afirmó que lucharía contra la corrupción y la violencia machista, y se mostraba favorable a la recuperación del 
estado del bienestar y a un cambio constitucional. El candidato de Podemos criticó que el gobierno estaba al servicio de unos pocos.

Las fotografías, vídeos y carteles que tuiteaba el candidato daban apoyo a sus publicaciones y se referían a los actos de campaña en los que participaba o a propuestas de gobierno, así como también publicó artículos y vídeos de las entrevistas que concedía a los medios. En la siguiente imagen se ve una foto de un acto de campaña:

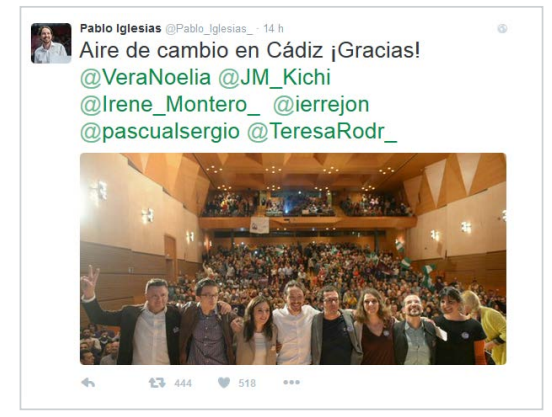

Durante la campaña electoral, Iglesias contestó algún comentario que le hicieron los simpatizantes. Entre los seguidores se establecieron algunos debates, aunque la mayoría de mensajes daban apoyo al candidato o lo criticaban.

En lo referente a la participación, Pablo Iglesias no solo pidió el voto a sus seguidores y simpatizantes con la etiqueta \#VotaPodemos20D, sino que también pidió un microcrédito para financiar la campaña electoral diciendo que "nuestra deuda es con la gente".

Cuadro 10: Nivel de “información”, “deliberación” y "participación” por parte de Pablo Iglesias

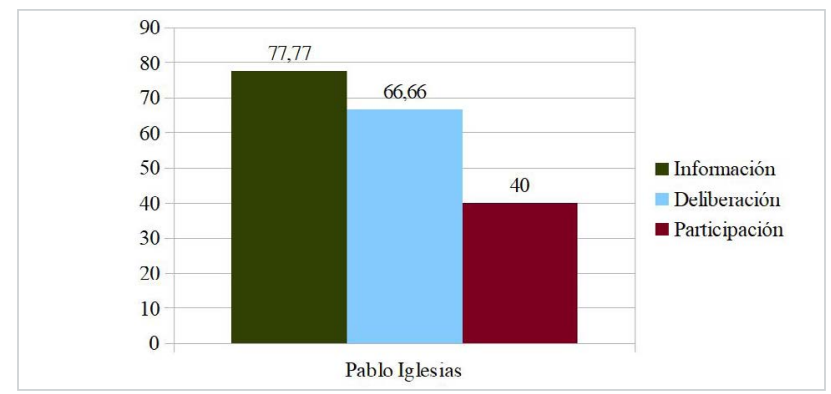

Fuente: elaboración propia 


\subsection{Discusión}

\subsubsection{Datos cualitativos}

El análisis comparativo de los datos cuantitativos referentes a las campañas de 2011 y 2015 y en relación al cuadro 11, nos muestra que Pablo Iglesias fue el candidato que tuvo más seguidores, mientras que fue Alfredo Pérez Rubalcaba, el que menos. No obstante, Rubalcaba ganó más seguidores durante el período electoral de 2011, que su sustituto Pedro Sánchez, que a su vez fue el candidato que menos seguidores consiguió en 2015.

Los datos nos muestran también que Alfredo Pérez Rubalcaba fue el candidato que más personas seguía, aunque ya no fue candidato en 2015, lo que muestra que ninguno de los otros candidatos lo superó. Mariano Rajoy fue el candidato que más personas seguía y el que más empezó a seguir; mientras que Pablo Iglesias fue el que menos personas seguía y el que menos personas empezó a seguir.

Cuadro 11: Número de seguidores y siguiendo a Twitter por parte de cada candidato en 2011 y 2015, comparativamente

\begin{tabular}{|c|c|c|c|c|c|c|}
\hline & $\begin{array}{c}\text { Seguidores } \\
\text { inicio campaña }\end{array}$ & $\begin{array}{l}\text { Seguidores fin } \\
\text { campaña }\end{array}$ & Diferencial & $\begin{array}{l}\text { Siguiendo inicio } \\
\text { campaña }\end{array}$ & $\begin{array}{l}\text { Siguiendo final } \\
\text { de campaña }\end{array}$ & Diferencial \\
\hline Mariano Rajoy (2011) & 78.920 & 112.176 & 33.256 & 2.505 & 2.657 & 152 \\
\hline Alfredo Pérez Rubalcaba (2011) & 50.678 & 77.151 & 26.473 & 7.225 & 7.354 & 129 \\
\hline Mariano Rajoy (2015) & 1.005 .274 & 1.043 .083 & 37.809 & 10.474 & 10.699 & 225 \\
\hline Pedro Sánchez (2015) & 212.268 & 233.750 & 21.482 & 5.799 & 5.819 & 20 \\
\hline Albert Rivera (2015) & 410.555 & 443.581 & 33.026 & 1.962 & 1.976 & 14 \\
\hline Pablo Iglesias (2015) & 1.345 .364 & 1.408 .513 & 63.149 & 1.889 & 1.894 & 5 \\
\hline
\end{tabular}

Fuente: elaboración propia

Según se desprende del cuadro 12, Alfredo Pérez Rubalcaba fue el que más tuits publicó durante la campaña electoral de 2011, y en 2015 no le superó ni su sucesor Pedro Sánchez, ni ningún otro candidato. Es interesante observar, también, que Mariano Rajoy fue el candidato que más tuits publicó en 2015 (aunque menos que en la campaña anterior), mientras que Pablo Iglesias fue el que menos actividad generó.

Mariano Rajoy fue el candidato que más retuits hizo durante su campaña electoral de 2015, en los que retuiteaba la actividad de su gobierno en funciones (por ejemplo, lo que se hacía desde la Moncloa o tuits que publicaba la vicepresidenta Soraya Sáenz de Santamaría).

Pablo Iglesias fue el candidato que menos retuits hizo y se referían a entrevistas que concedía a los medios de comunicación o fotos que publicaban otros miembros del partido en defensa del candidato de Podemos. 
Pedro Sánchez no respondió ninguna de las preguntas que se le plantearon, aunque Rubalcaba había respondido hasta 509 cuestiones en 2011. Cabe señalar también, que Rajoy rebajó su actividad, ya que contestó una pregunta, mientras que en la campaña de 2011 contestó un total de 575. El que más respuestas ofreció fue Albert Rivera, que contestó 21 preguntas.

También fue Pablo Iglesias el candidato que menos “me gusta” hizo en Twitter mientras que Rajoy, en 2015, fue el que más.

Cuadro 12: Número de tuits, retuits, respuestas y “me gusta” por parte de todos los candidatos en 2011 y 2015

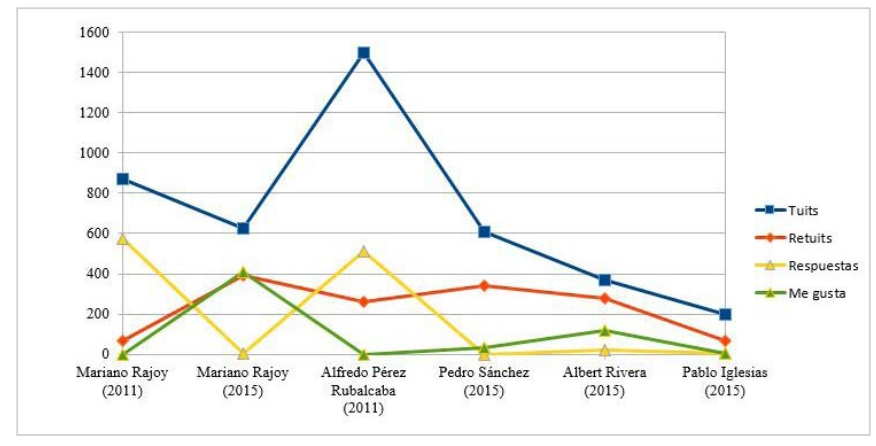

Fuente: elaboración propia partiendo de Tweetstats

Los datos cuantitativos demuestran que los candidatos prefirieron tuitear y difundir sus propuestas electorales. El número de retuits solo demuestra que intentaron hacer que los electores se sintieran más cercanos a los candidatos, pero en 2015 no establecieron una relación bilateral de diálogo tan alta como en 2011, cuando tanto Rajoy como Rubalcaba se propusieron responder a sus simpatizantes. El número de los "me gusta” también fue muy bajo en 2015 y tampoco determina una relación de igual a igual: el usuario solo sabe que el candidato o su equipo han leído el tuit, pero el candidato no demuestra interés en hablar con él.

\subsubsection{Datos cualitativos}

El cuadro 13 muestra el resultado del análisis de los datos cualitativos en 2011, y observamos que Alfredo Pérez Rubalcaba fue el candidato que mejor difundió la información en 2011 por delante de Mariano Rajoy. Ambos candidatos se esforzaron en promover la deliberación y entrar en contacto directo con sus seguidores, pero fue el candidato socialista el que hizo un paso más allá y promovió mejor la participación que su rival político. 
El uso de Twitter por parte de los principales candidatos en las campañas electorales para las elecciones...

Cuadro 13: Nivel de “información”, “deliberación” y “participación” por parte de Mariano Rajoy y Alfredo Pérez Rubalcaba, comparativamente en 2011

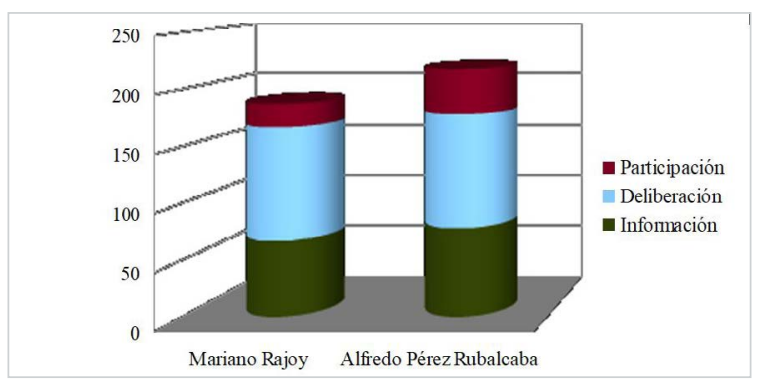

Fuente: elaboración propia

Pedro Sánchez y Albert Rivera fueron los candidatos que más se esforzaron en difundir toda la información relativa a la campaña electoral en 2015. Ambos candidatos, junto a Pablo Iglesias, fueron los candidatos que más trataron de deliberar con sus seguidores, y Mariano Rajoy el que menos, empeorando los resultados de 2011.

Pablo Iglesias sí fue el candidato que más hizo contribuir a la ciudadanía en la campaña electoral, junto a Rubalcaba que lo hizo en 2011. El resto de los candidatos no impulsaron tanto la participación, tal y como podemos ver en el cuadro 14.

Cuadro 14: Nivel de “información”, “deliberación” y “participación” por parte de Mariano Rajoy, Pedro Sánchez, Albert Rivera y Pablo Iglesias, comparativamente en 2015

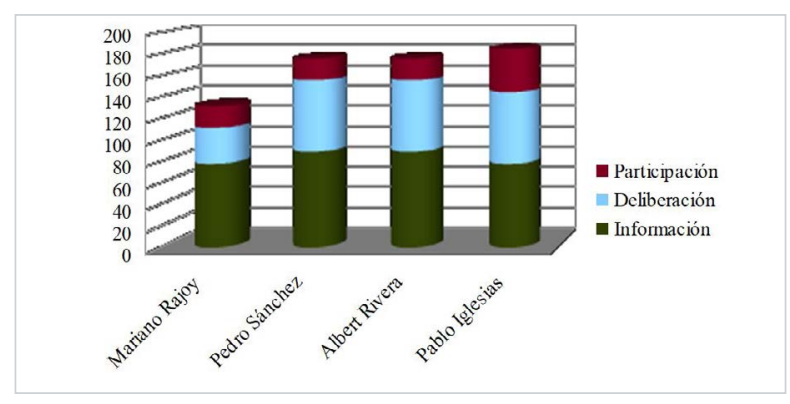

Fuente: elaboración propia

El cuadro 15 nos muestra los datos cualitativos comparados entre las campañas de 2011 y 2015. Pedro Sánchez y Albert Rivera fueron los candidatos que más difundieron información relativa a la campaña electoral en el conjunto de las dos campañas. Cabe destacar que el candidato socialista mejoró a Rubalcaba en 2011 y que Mariano Rajoy también mejoró.

Mariano Rajoy y Alfredo Pérez Rubalcaba fueron los candidatos que mejor fomentaron la deliberación en 2011 y los resultados fueron peores en 2015. Alfredo Pérez Rubalcaba en 2011 y Pablo Iglesias en 2015 fueron los candidatos que mejor promovieron la participación. 
Cuadro 15: Uso cualitativo de Twitter según las categorías de “información”, “deliberación” y “participación” de todos los candidatos en 2011 y 2015

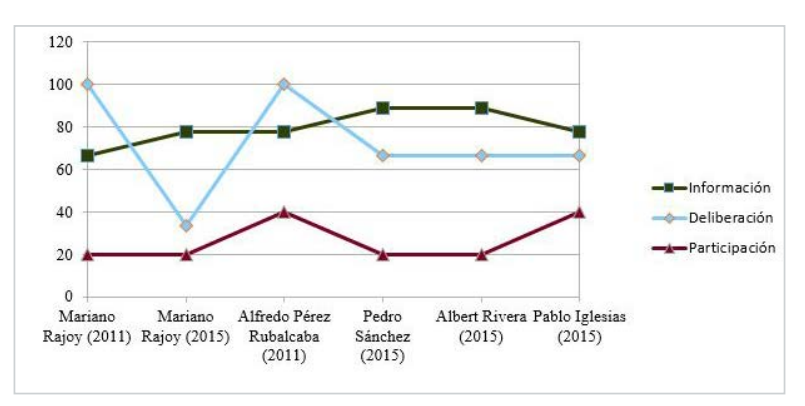

Fuente: elaboración propia

El cuadro 16 nos muestra los resultados cualitativos globales. Alfredo Pérez Rubalcaba fue el candidato que mejor usó Twitter, del que se pudieron responder afirmativamente 12 de las 17 preguntas que se planteaban. Mariano Rajoy empeoró el uso de Twitter: si en 2011 se habían respondido afirmativamente 10 preguntas, en 2015 se respondieron 9. Pablo Iglesias, Albert Rivera y Pedro Sánchez hicieron el mismo uso de Twitter: se pudieron responder afirmativamente $11 \mathrm{de}$ las 17 preguntas planteadas.

Cuadro 16: Uso cualitativo total de Twitter por parte de todos los candidatos, en 2011 y 2015 comparativamente

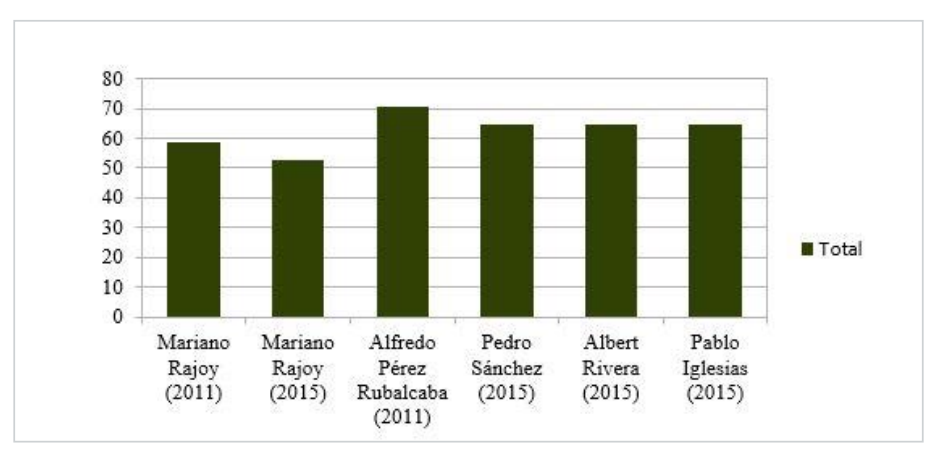

Fuente: elaboración propia

\section{Conclusiones}

A través de la comparación entre las campañas electorales para las elecciones generales de 2011 y 2015 y entre diferentes candidatos: Mariano Rajoy (PP) y Alfredo Pérez Rubalcaba (PSOE) en 2011; Mariano Rajoy (PP), Pedro Sánchez (PSOE), Albert Rivera (Ciudadanos) y Pablo Iglesias (Podemos) en 2015, la investigación se planteaba medir si se refleja una brecha generacional y digital entre los candidatos, partiendo de tres preguntas preliminares. 
Ante todo, nos planteábamos medir el uso cuantitativo de Twitter partiendo de la hipótesis de que los candidatos con un target de seguidores más jóvenes, Ciudadanos y Podemos, usarían más y mejor Twitter, mientras que los candidatos con un target de seguidores más mayor, PP y PSOE, no lo usarían tanto.

Los resultados cuantitativos nos muestran como, aparentemente, no se encuentra ninguna correlación entre target de votante y uso de Twitter. De hecho, si bien Pablo Iglesias fue el candidato que tuvo más seguidores y Alfredo Pérez Rubalcaba, el que menos, este último ganó más seguidores durante el período electoral de 2011, y, además, fue el candidato que más personas siguió. Asimismo, si por un lado en 2015, Pedro Sánchez fue el candidato que menos seguidores consiguió, por el otro, Mariano Rajoy fue el candidato que más personas seguía y el que más empezó a seguir; mientras que Pablo Iglesias fue el que menos personas seguía y el que menos personas empezó a seguir.

Finalmente, Rubalcaba fue el candidato que más tuiteó en el global de las dos campañas electorales, mientras que fue Pablo Iglesias el que menos, y Rajoy fue el candidato que más retuiteó en el global de las dos campañas y también el que más preguntas respondió en 2011, aunque en 2015 casi no lo hizo. En 2015 quien respondió a más preguntas fue Rivera, pero sin llegar al nivel de Rajoy en 2011. El candidato popular también fue el que más "me gusta" hizo, mientras que Pablo Iglesias fue el candidato que menos.

En términos de uso cuantitativo, por lo tanto, no solo no podemos afirmar que existe una brecha digital entre candidatos, sino que tenemos que afirmar que, de alguna forma, parece que la performance de 2011, especialmente la de los candidatos socialista y popular, superó la del 2015. Este dato se puede, de alguna manera, justificar con el “efecto Obama” (Beas, 2011; Casero-Ripollés, Feenstra y Tormey, 2016; Cervi y Roca, 2016; Costa, 2009; Enli, 2017b; Persily, 2017): las elecciones generales españolas de 2011 fueron las primeras después de la victoria, en 2008, del candidato demócrata Barack Obama, lograda gracias a novedosas estrategias en la Red, por lo que los candidatos de prácticamente todo los países intentaron subirse al "carro del ganador" imitando su modelo.

En términos cualitativos, nos preguntamos si los candidatos usarían Twitter como un medio tradicional o lo aprovecharían para generar una nueva relación y nuevas formas de interacción con los ciudadanos. La hipótesis que planteábamos era que los partidos más participativos promoverían más participación y deliberación, mientras que los menos se limitarían a informar. Y efectivamente, Pablo Iglesias fue quien más promovió la participación, pero con niveles no muy diferentes a los de Rubalcaba en 2011.

En cuanto a la deliberación, el diálogo con los ciudadanos, Mariano Rajoy y Alfredo Pérez Rubalcaba en 2011 tuvieron los resultados más altos, que no se repitieron en 2015. En realidad tenemos que destacar que, si bien hubo mucho feedback, la calidad de este no fue remarcable, es decir, en ningún momento se estableció una forma de diálogo abierta. Rajoy, por ejemplo, contestó a diferentes preguntas, pero remitiéndose al programa y, por lo tanto, sin generar un diálogo real.

Finalmente, nuestra hipótesis sobre el efecto contagio, es decir, que los candidatos de los nuevos partidos, supuestamente más acostumbrados al uso de las Redes Sociales, obligarían a los candidatos de la "vieja política" a usarlas más activamente, queda descartada.

Sin embargo, comparando los resultados de 2011 y de 2015, y considerando que en unas campañas electorales cada vez más profesionalizadas los candidatos cuentan con la ayuda de expertos equipos de comunicación que determinan 
las estrategias que hay que seguir en la Red, podríamos afirmar que si en el 2011 el efecto Obama llevó a experimentar nuevas herramientas, no sorprende que, una vez que se conoce el medio, los partidos tradicionales den un paso atrás especialmente en el diálogo con la ciudadanía. Esto es especialmente evidente en el caso de Rajoy, que siendo en el 2015 Presidente del Gobierno ya gozaba de suficiente visibilidad y, por lo tanto, no necesitaba tanto usar Twitter; además, probablemente tampoco resultaría muy interesante, desde el punto de vista estratégico, abrir nuevos espacio de diálogo con la ciudadanía.

En conclusión, por un lado podemos afirmar que, a nivel general, después de un comienzo esperanzador en 2011, los candidatos no parecen aprovechar las oportunidades que Twitter ofrece para establecer nuevas formas de interacción con la ciudadanía. Esto puede deberse, por un lado, a la cultura política española, para la cual la participación activa es algo nuevo, tanto desde el punto de vista de los políticos, como desde el punto de vista de los ciudadanos; y por el otro, a la disciplina y la jerarquía de cada partido, que no fomenta, sino más bien limita la libertad de maniobra de los candidatos. Por el otro lado, nuestra investigación se centró solo en los candidatos, por lo que sería interesante analizar estas mismas elecciones desde el punto de vista de los usuarios de las redes, para ver cómo reaccionaron a los inputs procedentes de la política y si generaron el interés hacia nuevas formas de relación con los políticos y la política.

Puesto que las redes ya son parte de la vida cotidiana de cada ciudadano, si las empresas y el marketing han hecho enormes pasos adelante en lo que denominan engagement, considerando las Redes Sociales como un vehículo para crear y mejorar la relación con los consumidores (Perks y Sedley, 2008), la política tendrá que adaptarse. El desarrollo de la participación online, junto con la enorme cantidad de datos que las redes ponen a nuestra disposición, abren nuevas oportunidades de investigación. Siendo los Internet studies un campo nuevo y de manera inherente, multidisciplinarios, no existe unanimidad referente al sistema metodológico: los autores proponen un elevado y disperso número de prácticas que no contribuyen a unificar criterios. Tal y como señalan Jürgens y Jungherr (2016): "Only by being able to write and read code, will you be able to directly interact with a service's API and thus be able to make and assess design choices while keeping in mind their consequences for the interpretation of patterns emerging subsequent analyses." (Jürgens y Jungherr, 2016: 13).

Por lo tanto, es preciso afinar nuestras herramientas metodológicas para mejorar cada vez más la precisión de los instrumentos a nuestra disposición. En nuestro caso, por ejemplo, midiendo los niveles de deliberación nos hemos dado cuenta que, tal y como anteriormente mencionábamos, si bien sobre todo Rajoy y Rubalcaba en 2011 obtuvieron resultados muy altos en esta categoría, constatamos que en realidad lo que hicieron en mayor parte es remitir sus respuestas al programa electoral en vez de generar un debate abierto con la ciudadanía.

No obstante, si bien admitimos que hay márgenes de mejora, consideramos que nuestro aporte metodológico resulta eficaz para poder medir el uso que los candidatos hacen de las Redes Sociales, y que, por esto, podría ser aplicable mediante las relativas adaptaciones, a otras redes, como por ejemplo Instagram, que se usa cada vez más, tanto para la comunicación corporativa como para la política. 
El uso de Twitter por parte de los principales candidatos en las campañas electorales para las elecciones...

\section{Referencias bibliográfica}

Abejón, P.; Sastre, A.; y Linares, V. (2012): “Facebook y Twitter en campañas electorales en España”, Anuario Electrónico de Estudios en Comunicación Social Disertaciones, n. 5, pp. 129-159. http://erevistas.saber.ula.ve/index.php/Disertaciones/ [Consultado: 30/11/2017].

Almond, G.; y Verba, S. (1963): The Civic Culture: Political Attitudes and Democracy in Five Nations. Princeton. Princeton University Press.

Anduiza, E. (2009): “Internet, campañas electorales y ciudadanos: el estado de la cuestión”, Quaderns del CAC, n. 33, pp. 5-12.

Barber, B. (1984): Strong Democracy, participatory politics for a new age. Berkley: University of California Press. Beas, D. (2011): La reinvención de la política. Obama, Internet y la nueva esfera pública. Barcelona: Ediciones Península. Carpentier, N. (2016): "Beyond the Ladder of Participation: An Analytical Toolkit for the Critical Analysis of Participatory Media Processes”, Javnost - The Public, 23:1, pp. 70-88. DOI: 10.1080/13183222.2016.1149760 [Consultado: 03/04/2017].

Casero-Ripollés, A.; Feenstra, R.A.; y Tormey, S. (2016): "Old and New Media Logics in an Electoral Campaign: The Case of Podemos and the Two-Way Street Mediatization of Politics”, The International Journal of Press/Politics, v. 21, pp. 378-397. DOI: 10.1177/1940161216645340 [Consultado: 05/12/2017].

Casero-Ripollés, A.; Sintes-Olivella, M.; y Franch, P. (2017): “The Populist Political Communication Style in Action: Podemos's Issues and Functions on Twitter During the 2016 Spanish General Election”, American Behavioral Scientist, v. 61, pp. 986-1001. DOI: 10.1177/0002764217707624 [Consultado: 05/12/2017].

Casero-Ripollés, A, Miquel-Segarra, S. y Alonso-Muñoz, L. (2016): “El potencial dialógico de Twitter en campaña electoral. El caso de PSOE y Podemos en España”, Iberian conference on information systems and technologies (Cisti), 15-18 de junio. DOI: 10.1109/CISTI.2016.7521592 [Consultado: 03/12/2017].

Cervi, L.; y Roca, N. (2017): "La modernización de la campaña electoral para las elecciones generales de España en 2015. ¿Hacia la americanización?”, Comunicación y Hombre. Revista interdisciplinar de ciencias de la comunicación y humanidades, n. 13, pp. 133-150. https://comunicacionyhombre.com/article/ la-modernizacion-la-campana-electoral-las-elecciones-generales-espana-2015/

Costa, P.O. (2009): “La utilització d'Internet per part de Barack Obama transforma la comunicació”, Quaderns del CAC, n. 33, pp. 35-41. http://www.cac.cat/pfw_files/cma/recerca/quaderns_cac/q33_costa.pdf [Consultado: 12/12/2011].

Dader, J. L. (2009): “Ciberpolítica en los websites de partidos políticos: la experiencia de las elecciones de 2008 en España antes las tendencias transnacionales”, Revista de sociologia e política. v. 17, n. 34, pp. 45-62. http://www.scielo.br/pdf/ rsocp/v17n34/a05v17n34.pdf [Consultado: 2/06/2012].

Davis, R. (2005): Politics online. New York: Routledge.

Del Rey Morató, J. (2007): Comunicación política, Internet y campañas electorales. Madrid: Tecnos.

Duverger, M. (1957): Los partidos políticos. México: Fondo de Cultura Económico. 
Enli, G. (2017a): "New media and politics, article in Annals of the International Communication Association", Annals of the International Communication Association, v. 41, pp. 220-227. DOI: 10.1080/23808985.2017.1392251 [Consultado: 05/12/2017].

(-) (2017b): "Twitter as arena for the authentic outsider: exploring the social media campaigns $\quad$ of Trump and Clinton in the 2016 US presidential election", European journal of communication, v. 32, n. 1, pp. 50-61. DOI: 10.1177/0267323116682802 [Consultado: 05/12/2017].

Enli, G.; y Skogerbø, E. (2013): “Personalized campaigns in party-centred politics: Twitter and Facebook as arenas for political communication", Information, communication and society, v. 16, n. 5, pp. 757-774. DOI: 10.1080/1369118X.2013.782330 [Consultado: 05/12/2017].

Font, J.; y Blanco, I. (2005): “¿Qué hay detrás de la oferta de participación? El rol de los factores instrumentales e ideológicos en los mecanismos españoles de participación”, Revista del CLAD Reforma y Democracia.n.31. http://old.clad.org/portal/ publicaciones-del-clad/revista-clad-reforma-democracia/articulos/031-febrero-2005/bfque-hay-detras-de-la-ofertade-participacion-el-rol-de-los-factores-instrumentales-e-ideologicos-en-los-mecanismos-espanoles-de-participacion [Consultado: 10/03/2018].

Freelon, D.; y Karpf, D. (2015): "Of big birds and bayonets: hybrid Twitter interactivity in the 2012 presidential debates”, Information, communication and society, v. 18, n.4, pp. 390-406. DOI: 10.1080/1369118X.2014.952659 [Consultado: 02/12/2017].

Gibson, R. K.; y Römmele, A. (2007): Political Communication, en Danièle Caramani (ed.): Comparative Politics. Oxford: Oxford University Press. http://www.politikkampagnen.de/politikkampagnen/documents/pdf/c19-gibsonandroemmele_rg_28_04_07.pdf [Consultado: 11/01/2013].

Hallin, D.C.; y Mancini, P. (2004): Comparing media systems: three models of media and politics. Cambridge: Cambridge University Press.

Jungherr, A. (2014a): “Twitter in Politics: A Comprehensive Literature Review”. http://dx.doi.org/10.2139/ssrn.2402443 [Consultado: 05/06/2017].

(-) (2014b): “The logic of political coverage on Twitter: Temporal dynamics and content”, Journal of communication, v. 64, n. 2, pp. 239-259. https://doi.org/10.1111/jcom.12087 [Consultado: 23/01/2018].

(-) (2016): “Twitter use in election campaigns: A systematic literature review”, Journal of Information Technology \&

Politics, 13:1, pp. 72-91. DOI: 10.1080/19331681.2015.1132401

Jürgens, P. \& Jungherr, A. (2016): A Tutorial for using Twitter data in the social sciences: data collection, preparation and analysis. http://dx.doi.org/10.2139/ssrn.2710146 [Consultado: 23/01/2018].

Kalnes, Ø. (2009): “¿E-ruptura en la política de partidos? El caso del Web 2.0 y los partidos noruegos”, Quaderns del CAC, $\mathrm{n}$. 33, pp. 63-76. http://www.cac.cat/pfw_files/cma/recerca/quaderns_cac/Q33_Kalnes_ES.pdf [Consultado: 03/11/ 2012]. 
El uso de Twitter por parte de los principales candidatos en las campañas electorales para las elecciones...

Kirchheimer, O. (1966): “The Transformation of the Western European Party Systems”, en LaPalombara, J. Y Weiner, M. (ed): Political Parties and Political Development. Princeton, NJ. Princeton Univeristy Press, pp. 177-200. DOI: 10.1515/9781400875337-007 [Consultado: 23/12/2016].

Kluver, R.; et al. (2007): The Internet and National Elections. A comparative study of web campaigning. NewYork: Routledge. Larsson, A.O.; y Moe, H. (2014): “Triumph of the Underdogs? Comparing Twitter Use by Political Actors During Two Norwegian Election Campaigns”, SAGE Open, pp. 1-13. DOI: 10.1177/2158244014559015 [Consultado:07/12/2017].

Lee Kaid, L.; y Holtz-Bacha, C. (1995): Political advertising in Western democracies. California: SAGE Publications.

Lijphart, A. (1971): “Comparative Politics and the Comparative Method”, The American Political Science Review, v. 65, n. 3, pp. 682-693. http://homepages.wmich.edu/ plambert/comp/lijphart.pdf [Consultado: 20/10/2016].

(-) (1999): Patterns of democracy. Government forms and Performance in Thirty Six Countries. New Haven: Yale University Press.

Lilleker, D.G; y Vedel, T. (2013): “The Internet in campaigns and elections”, en Dutton, W.H. (Ed): The Oxford handbook of Internet Studies. Oxford, England: Oxford University Press, pp. 401-420.

Lilleker, D.G. et al. (2011). "Informing, Engaging, Mobilising or Interacting: Searching for a European model of web campaigning”, European Journal of Communication, pp.195-213. http://paperroom.ipsa.org/papers/paper_4133.pdf [Consultado: $15 / 10 / 2013$ ].

Lipset, S. M.; y Rokkan, S. (1967): Party Systems and Voter Alignments. Free Press.

Machado, N.; y Capdevila, A. (2016): “Interacción y debate en Twitter en las elecciones españolas de mayo de 2015”, Obra Digital Revista de Comunicación. n. 11, pp. 61-83. http://www.raco.cat/index.php/ObraDigital/article/view/315497 [Consultado: 17/02/17].

Negrine, R.; y Papathanassopoulos, S. (1996): “The ‘Americanization’ of Political Communication. A Critique”, The International Journal of Press/Politics, 1(2), pp. 45-62. https://www.researchgate.net/publication/249809150_The_Americanization_of_Political_CommunicationA_Critique [Consultado: 21/12/2016].

Norris, P. (2000). A virtuous circle. New York: Cambridge University Press.

(-) (2001). Digital Divide. New York: Cambridge University Press.

Perks, M.; y Sedley, R. (2008): Winners and Losers in a troubled economy. How to engage customers online to gain competitive advantatge. London: cScape Strategic Internet Services Ltd.

Persily, N. (2017): “Can democracy survive the Internet?”, Journal of democracy, v. 28, n. 2, pp. 63-76. (2017). https:/ /www. journalofdemocracy.org/sites/default/files/07_28.2_Persily\%20\%28web\%29.pdf [Consultado: 25/11/2017]

Peytibi, F. X; Rubio, R.; y Gutiérrez-Rubí, A. (2009): “La campaña electoral española en Internet, un año después y a un año vista”. http://www.gutierrez-rubi.es/wp-content/uploads/2009/03/la_campana_electoral_espanola_un_ano_despues_gutierrez_peytibi_rubio.pdf [Consultada: 03/03/2012]. 
Rodríguez, R.; y Ureña, D. (2012): “Diez razones para el uso de Twitter como herramienta en la comunicación política y electoral”, Comunicación y Pluralismo, n. 5, pp. 89-116

Sartori, G. (1970): “Concept misformation in comparative politics”, The American Political Science Review, v.64, n.4, pp.10331053. http://www.la.utexas.edu/users/chenry/core/Course\%20Materials/Sartori/0.pdf [Consultado: 05/10/2016].

(-) (1980) Partidos y sistemas de partidos, v. I. Madrid: Alianza Editorial.

(-) (2003). ¿Qué es la democracia? Madrid: Taurus.

Scammell, M. (1997): “The wisdom of the war room: US Campaigning and Americanization”, The Joan Shorenstein Center. Press Politics. Public Policy. Harvard University, pp. 1-22. https://shorensteincenter.org/us-campaigning-and-americanization/ [Consultado: 22/01/2017].

Schneider, S. M.; y Foot, K. A. (2002): “Online structure for political action: exploring presidential campaign web sites from the 2000 american election”, The Public, pp. 1-18. https://people.sunyit.edu/ steve/schneider-foot-online-structure-javnost.pdf [Consultado: 27/04/2013].

(-) (2004): “The web as an object of study”, New Media and Society, 6(1), pp. 114-122. http://faculty.washington.edu/ kfoot/Publications/Web-as-Object-of-Study.pdf [Consultado: 13/10/2013].

Skogerbø y Krumsvik (2014): “Newspapers, Facebook and Twitter. Intermedial agenda setting in local election campaigns”, Journalism Practice, pp. 350-366.

Strömbäck, J.; y Kiousis, S. (2014): “Strategic Political Communication in Election Campaigns”, en Reinemann, C. (ed), Political Communication, pp.109-128. https://www.researchgate.net/publication/263353301_Strategic_Political_Communication_in_Election_Campaigns [Consultado: 03/12/2017].

Swanson, D. L. (1995): “El campo de comunicación política. La democracia centrada en los medios”, en Muñoz-Alonso, A.y Rospir, J. I. (eds.). Comunicación Política. Madrid: Universitas.

Talbot, D. (2008): "How Obama Really Did It. The social-networking strategy that took an obscure senator to the doors ofthe White House”, MIT Technology Review. http://fpdzn.fastimap.com/Images/junk/obama_tech.pdf [Consultado: 20/03/2018].

Vergeer, M. (2016): “Adopting, Networking, and Communicating on Twitter: a Cross-National Comparative Analysis", Social Science Computer Review, pp. 1-15. DOI: 10.1177/0894439316672826 [Consultado: 01/12/2017].

Vergeer, M.; y Cunha, C. (2009): CENMEP coding scheme Candidate and party websites European Parliament Elections 2009. Radboud University: Nijmegen .

Vergeer, M.; y Hermas, L. (2013): “Campaigning on Twitter Micro-blogging and online social networking as campaign tools in the 2010 general elections in the Netherlands”, Journal of Computer-Mediated Communication, n. 18, pp. 399-419.

https://onlinelibrary.wiley.com/doi/abs/10.1111/jcc4.12023 [Consultado: 15/06/2014]. 
El uso de Twitter por parte de los principales candidatos en las campañas electorales para las elecciones...

Vergeer, M.; Hermans, L.; y Cunha, C. (2013): "Web campaigning in the 2009 european parliament elections: a cross national comparative analysis", New Media \& Society, v. 15, n. 1, pp. 128-148. http://journals.sagepub.com/doi/ abs/10.1177/1461444812457337?journalCode=nmsa [Consultado: 15/06/2014].

Zugasti, R.; y Sabés, F. (2015): “Los issues de los candidatos en Twitter durante la campaña de las elecciones generales de 2011", Zer-Revista de Estudios de Comunicación, v. 20. n. 38 pp. 161-178. http://www.ehu.eus/ojs/index.php/Zer/article/ view/14792/13072 [Consultado: 02/12/2017]. 